\title{
Montelukast y diarrea sanguinolenta: una asociación infrecuente a tener en cuenta
}

\author{
I. Carabaño Aguadoa, L. Llorente Otones ${ }^{b}$ \\ aServicio de Pediatría. Hospital Infanta Elena. Valdemoro, Madrid. España.

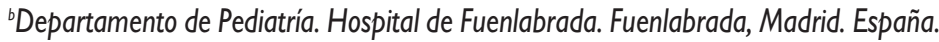

Fecha de publicación en Internet: 12 de noviembre de 2010

\section{Resumen}

El montelukast es un fármaco seguro ampliamente prescrito. Como en cualquier producto sanitario, su utilización no está exenta de efectos adversos, algunos de los cuales son poco frecuentes. Se presenta un caso clínico de diarrea mucosanguinolenta que afectó a una niña de cuatro años, y que se resolvió de forma espontánea tras la retirada del fármaco. En el presente artículo se revisa el mecanismo de acción del montelukast, sus indicaciones, sus efectos secundarios más frecuentes, así como el razonamiento para sospechar que un fármaco puede estar detrás de un determinado efecto adverso.

Palabras clave: Montelukast. Leucotrieno. Diarrea. Hemorragia. Efecto adverso.

Montelukast and bleeding diarrhoea: an unusual association to be considered

Abstract

Montelukast is a safe drug widely prescribed. As with any medical device, its use is related with some side effects, some of which are rare. We report a case of bleeding diarrhea in a four year old girl, which was resolved spontaneously after drug withdrawal. This article reviews the mechanism of action of montelukast, its indications, its most common side effects, and the evidences to suspect that a drug may be behind a certain adverse effect.

Key words: Montelukast. Leukotriene. Diarrhoea. Bleeding. Side effect.

\section{Introducción}

El montelukast fue el producto sanitario más prescrito durante el año 2007 en Estados Unidos ${ }^{1}$. Como cualquier fármaco seguro, su utilización no se en- cuentra exenta de efectos adversos ${ }^{2}$. En este artículo se presenta un caso clínico en el que se vinculó su consumo con la aparición de un cuadro de diarrea mucosanguinolenta.

Iván Carabaño Aguado, carabano1975@hotmail.com

Los autores declaran no presentar conflictos de intereses en relación con la preparación y publicación de este artículo. 


\section{Caso clínico}

Niña de cuatro años de edad, normoconfigurada, sin antecedentes familiares de interés, que acude remitida a la consulta de Gastroenterología Infantil de nuestro hospital por cambio en el hábito intestinal. En los últimos cuatro meses, pasó de emitir una deposición normal en días alternos a emitir una o dos deposiciones diarias, blandas, con moco y hebras de sangre roja. No consta dolor abdominal, fiebre, vómitos, hiporexia o astenia. Curva ponderoestatural ascendente. La madre no refería tampoco la aparición de aftas orales ni lesiones cutáneas, articulares o perianales. Entre sus antecedentes personales destacó alergia a avellanas y pescado blanco, así como episodios repetidos de broncoespasmo, en relación con infecciones respiratorias. Para el manejo de estos episodios, su pediatra le pautó salbutamol inhalado en cámara presurizada, administrado a demanda; y desde hace seis meses montelukast, a razón de 4 mg diarios.

En la consulta de Gastroenterología se solicitó hemograma, bioquímica general, inmunoglobulina $A$, anticuerpos de celiaquía, estudio de coagulación, coprocultivo, y detección de virus y parásitos en heces, todos ellos con resultado negativo. El día que se le informó a la madre de la llegada de los resultados, esta nos comentó que había suspendido la administración de montelukast, pues había leído en el prospecto que su administración aumentaba el riesgo de sangrado, y que, coincidiendo cronológicamente con la supresión, el ritmo intestinal de la niña se había normalizado. De hecho, sigue siendo normal tras 12 meses de seguimiento.

\section{Comentarios}

El montelukast es un antagonista del leucotrieno D4 en el receptor leucotriénico cisteinílico CysLT1, presente en las vías respiratorias. La unión de los cisteinil-leucotrienos a sus receptores se ha relacionado con la aparición de edema traqueal, broncoconstricción y aumento de la producción de moco viscoso. De forma conceptual, la inhibición de esta unión consigue un efecto antiasmático ${ }^{3}$. El montelukast está indicado para el manejo del asma persistente leve-moderada, en el escalón 2, como alternativa de los corticoides inhalados en dosis bajas; y en los escalones 3, 4 y 5 como tratamiento adicional a los corticoides inhalados. Por último, está indicado en la profilaxis del asma inducida por el ejercicio ${ }^{4}$. Además, se ha postulado su utilidad en el tratamiento de la rinitis alérgica, en las sibilancias en relación 
con infecciones víricas, en la poliposis nasal, en la dermatitis atópica y en una miscelánea de procesos (migraña, sinusitis alérgica, urticaria crónica, enfermedad pulmonar obstructiva crónica, conjuntivitis alérgica, mastocitosis, fibrosis pulmonar idiopática y cistitis intersti(ial) $)^{4,5}$.

Sus reacciones adversas más frecuentes son: cefalea, astenia, somnolencia, fiebre, dolor abdominal, dispepsia, gastritis, fiebre, dolor dental, mareos, congestión nasal, tos, rash maculopapular, irritabilidad e insomnio. Más raramente, se ha documentado riesgo de sangrado, infiltración eosinofílica en hígado y desarrollo del síndrome de Churg-Strauss ${ }^{6}$. Algunos estudios han señalado que la aparición de diarrea, faringitis, laringitis, sinusitis, náuseas, otitis e infecciones víricas es más frecuente si el montelukast se administra a pacientes pediátricos ${ }^{7}$.

¿Por qué pensamos que nuestra paciente presentaba una diarrea sanguinolenta como efecto adverso del montelukast? Básicamente, porque se cumplían los criterios de causalidad ${ }^{8}$. Estos son: 1) Secuencia temporal: el fármaco se estaba administrando de manera concomitante a la aparición del efecto. 2) Plausibilidad biológica: los receptores de leucotrienos están presentes en el intestino. Su papel allí está por aclarar, si bien se es- pecula sobre su participación como mediadores en diversos procesos que pueden cursar con diarrea e inflamación, tales como la enfermedad celíaca y la enfermedad de Crohn', y en otros que pueden cursar con diarrea, como el síndrome de intestino irritable. Por otro lado, el efecto sobre los vasos sanguíneos de los cisteinilleucotrienos también está por definir, se ha demostrado la presencia de receptores para los mismos en las células endoteliales ${ }^{10}$. 3) Ausencia de causa alternativa que explique el problema: se descartaron las causas infecciosas, los trastornos de la coagulación y la hemostasia, la paciente no presentaba estreñimiento. 4) Mejoría del problema tras la retirada del fármaco: se constató la misma. 5) Conocimiento previo de la reacción en la literatura científica: se notificó la reacción adversa al Centro de Farmacovigilancia de la Comunidad de Madrid, y se solicitó un informe técnico. En el mismo, se nos comentó lo siguiente: "En la base del Sistema Español de Farmacovigilancia, FEDRA, tenemos recogidas 422 notificaciones espontáneas que se sospechan producidas por montelukast; de ellas, en cuatro se recoge algún tipo de hemorragia gastrointestinal, dos son cuadros de hematemesis, en niños de 12 y 17 años, uno es una hemorragia gastrointestinal no especificada en un niño de seis años, y hay una diarrea con 
sangre. En el Reino Unido, hasta el 28 de abril de 2010 se han recibido 1614 notificaciones, en 13 se recogen hemorragias gastrointestinales".

En casi todos los fármacos comercializados se han notificado efectos adversos sobre el tubo digestivo, pero los que con mayor frecuencia se han vinculado con la aparición de diarrea son los laxantes, los antibióticos (en especial los del grupo de betalactámicos) y algunos quimioterapéuticos ${ }^{11}$.

Pensamos que la divulgación de este caso puede ser útil, pues la diarrea mucosanguinolenta prolongada es un motivo de alarma, de derivación al especia- lista y de consumo de recursos por parte del sistema sanitario. Estimamos que conviene pensar en la posibilidad de que el montelukast pueda jugar un papel en la misma, siempre y cuando se hayan descartado otras causas, antes de la realización de exploraciones complementarias invasivas, como la colonoscopia, si el paciente que tenemos entre manos lo está consumiendo.

\section{Agradecimientos}

Agradecemos a Carmen Ruiz Ibáñez, del Centro de Farmacovigilancia de la Comunidad de Madrid, la información proporcionada.

\section{Bibliografía}

1. Diamant Z, Mantzouranis E, Bjermer L. Montelukast in the treatment of asthma and beyond. Expert Rev Clin Inmunol. 2009;5:639-58.

2. Tamesis GP, Covar RA. Long-term effects of asthma medications in children. Curr Opin Allergy Clin Inmunol. 2008;8:163-7.

3. Del Giudice MM, Pezzulo A, Capristo C, Alterio $E$, Caggiano S, De Benedictis D, et al. Leukotriene modifiers in the treatment of asthma in children. Ther Adv Respir Dis. 2009;3:245-51.

4. Sociedades Españolas de Alergología e Inmunología Clínica, Neumología y Cirugía Torácica, Otorrinolaringología y Cirugía Facial, Medicina de Familia y Comunitaria, Médicos de Atención Primaria, Médicos Generales y de Familia, Respirato-

rio de Atención Primaria, Inmunología Clínica y Alergia Pediátrica, Neumología Pediátrica y Foro Español de Pacientes. Guía Española para el manejo del asma. 2009; p. 43-59. Disponible en www. gemasma.com [consultado el 30/06/2010].

5. Phan $H$, Moeller ML, Nahata MC. Treatment of allergic rhinitis in infants and children: efficacy and safety of second-generation antihistamines and the leukotriene receptor antagonist montelukast. Drugs. 2009;69:2541-76.

6. Bisgaard H, Skoner D, Boza ML, Tozzi CA, Newcomb K, Reiss TF, et al. Safety and tolerability of montelukast in placebo-controlled pediatric studies and their open-label extensions. Pediatr Pulmonol. 2009;44:568-79.

7. Van Adelsberg J, Moy J, Wei LX, Tozzi CA, Knorr B, Reiss TF. Safety, tolerability and explora- 
tory efficacy of montelukast in 6-to-24-month-old patients with asthma. Curr Med Res Opin. 2005; 21:971-9.

8. Brunlöf G, Tukukino C, Wallerstedt SM. Individual case safety reports in children in commonly used drugs groups. BMC Clin Pharmacol. 2008;8:1-5.

9. Reims A, Redfors S, Sjövall H, Strandvik B. Cysteinil leukotrienes are secretagogues in atrophic coeliac and in normal duodenal mucosa of children. Scand J Gastroenterol. 2005;40: 160-8.

10. Uzonyi B, Lötzer K, Jahn S, Kramer C, Hildner $M$, Bretschneider $E$, et al. Cysteinil leukotriene 2 receptor and protease-activated receptor 1 activate strongly correlated early genes in human endothelial cells. Proc Natl Acd Sci USA. 2006;18: 6326-31.

11. Vaishnavi C. Clinical spectrum and pathogenesis of C. difficile associated diseases. Indian J Res. 2010;131:487-99. 